\title{
Study of Microstructures on Cross Section of JAPANESE SWORD
}

\author{
M. Yaso ${ }^{\text {a }, ~ T . ~ T a k a i w a, ~ Y . ~ M i n a g i, ~ K . ~ K u b o t a ~}{ }^{1}$,

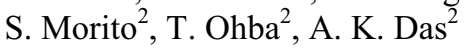 \\ Wakoh Museum, Yasugi-cho, Yasugi 692-0011, JAPAN \\ ${ }^{1}$ Metallurgical Research Laboratory, Hitachi Metals, Ltd., Yasugi-cho, Yasugi 692-8601, JAPAN \\ ${ }^{2}$ Department of Materials Science, Shimane University, Nishikawatsu, Matsue 690-8504, JAPAN
}

\begin{abstract}
An old, famous Japanese sword has been studied metallurigically to observe its microstructure by optical microscopy and scanning electron microscopy. The microstructure in the sharp edge of cross-sectional part is fine martensite and the morphology is lath type martensite. The other parts of sword, side and central part, of cross section show the structure of fine pearlite or coarse pearlite dominantly. The hardness of the sharp edge is high enough to possess the sharp cutting property. SEM-EDX observations indicated that several kinds of non-metallic inclusions exist in the sword which are considered to be originated from the slag smelting reaction in Tatara process. The amount of non-metallic inclusions in the sword is 50-100 times more than that of the ordinary steel. In the sharp edge the amount of inclusions is fewer and the sizes are finer in comparison with side and central part of the sword. It is considered that repeatedly forging and folding operations in making sword process are responsible for that.
\end{abstract}

\section{Introduction}

There are Japanese sword and Damascus sword [1] as a famous one in the world historically and technically. Japanese sword [2-6] has long history more than one thousand years. Its excellent sharp cutting property and beautiful appearance have been well known to a number of people in the world. It is considered that those are, in fact, attributed to the raw materials and the producing process. In making Japanese sword, the special steel called "Tamahagane [7,8]" smelted with Tatara [9-12] process has to be used, otherwise good Japanese sword cannot be produced. Tatara is the unique and traditional steel making process since old times in Japan. The blocks of Tamahagane steel are folded a dozen of times and are heated and forged by Japanese sword craftsman, swordsmith. Then after quenched and polished process, Japanese sword is produced. As the result of these processes, the Japanese sword is hardly broken nor bent and possesses sharp cutting property. These properties mostly depend on the micro structures which are influenced by the making process of Japanese sword.

Many excellent Japanese swords are usually said to be found in the period of 11th-16th century in Japan. Nowadays most of swordsmiths are trying to produce the sword of same quality of the old sword.

Tawara [13] was a pioneer of Japanese sword and had studied the micro structure of several Japanese swords regarding old sword (1st generation, made during 11th-16th century), 2nd generation (made during 16th18th century) and 3rd generation sword (made during 18th-19th century) and modern sword. He pointed out that "Hamon (in Japanese)", which is several kinds of wavy patterns shown on the sword surface, was composed of martensite structure and troostite (fine pearlite) structure with optical microscopy. Takahashi et al. [14] had investigated the fundamental properties such as microstructure, micro hardness, chemical composition and nonmetallic inclusion about old sword and 2nd generation sword. Kitada [15] had reported the microstructure and non-metallic inclusion on some old sword. Although many attentions have been attracted, there are a few references written in English, unfortunately. Further, the precise metallurgical characteristics of Japanese sword have not been clear yet. In this paper the micro structural analyses as well as the non-metallic inclusions in the famous old sword is reported.

\footnotetext{
${ }^{a}$ e-mail : yasoke_youkoso@yahoo.co.jp
} 


\section{Experimental Procedure}

The specimen was taken from an old sword which was produced by the 2nd generation of Muramasa about 600 years ago. The sword was named after him and called 'Muramasa 2nd'. A small piece was cut from the original sword having the size $4 \mathrm{~mm}$ (thickness) $\times 22 \mathrm{~mm}$ (width) $\times 4 \mathrm{~mm}$ (length) for experimental observations. The chemical composition is shown in Table1.

Table 1. Chemical composition of the specimen (mass\%)

\begin{tabular}{|c|c|c|c|c|}
\hline $\mathrm{C}$ & $\mathrm{Mn}$ & $\mathrm{P}$ & $\mathrm{S}$ & $\mathrm{Cu}$ \\
\hline 0.72 & Lap & 0.005 & 0 & 0.017 \\
\hline
\end{tabular}

As this composition was analyzed through machined chips from the cross section, each composition is the average value of the cross section. The sharp edge part was also analyzed by Electron Probe Micro-Analyze (EPMA), and was shown that the carbon content is found to be 0.78 mass $\%$. It is known that quantity of carbon influences performance of Japanese sword and its level is pointed to be $0.5 \sim 0.7 \mathrm{mass} \%$ in the greater part of Japanese swords. The harmful impurities such as P, S, Cu and Mn are low, which exerted sword quality.

The specimen polished was etched with nital and observed by optical microscopy (OM) and scanning electron microscopy (SEM). Three specific zones in cross section were observed; that is, (i) sharp edge, (ii) side part, (iii) centeral part. Micro Vickers hardness was measured in different zone of the specimen.

A lot of non-metallic inclusions were reported to be distributed in Japanese sword [14, 16], but those details had not been studied enough up to now. The size distribution and the area percentage of non-metallic inclusions above three specific zones were measured with the image analysis soft "WinRoof" developed by Microsoft co. The area percentage was considered to be volume percentage, although the non-metallic inclusions are distributed three dimensionally. The composition of these inclusions was analyzed by energy dispersive Xray Spectroscopy with SEM .

\section{Results and Discussion}

\subsection{Micro structure observation with OM and SEM}

Fig. 1 shows the microstructures of cross section in Muramasa 2nd by OM and SEM. Three specific zones in cross section were observed; that is, (i) sharp edge, (ii) side part, (iii) centeral part. The grain size of sharp edge part is observed to be very fine, about $10-15 \mu \mathrm{m}$ as a result of the effect of 10 several times-forgings in sword making process. The distribution of martensite structure is limited only to the sharp edge of the sword and in other areas fine pearlite or coarse pearlite structures are observed dominantly. The morphology of the martensite in the sharp edge is lath type. Maki et al. [17] investigated the metallurgical characterisics of lath martensite structure in plain carbon commercial steels containing up to $0.8 \mathrm{mass} \% \mathrm{C}$. They indicated the change in morphology of lath martensite structure with carbon content. In the carbon content of $0.1-0.6 \mathrm{mass} \% \mathrm{C}$, the morphology of martensite was lath type. In the 0.8 mass $\% \mathrm{C}$, a lenticular martensite occasionally formed although the lath martensite dominated. In our study of this sword, lenticular martensite are not obserded.

In addition, the macro structure of Muramasa 2 nd is found to be a good structure, because there were none of micro cracks nor inside oxide scales which happened to be formed during repeated folding and forging operation.

\subsection{Micro hardness distribution}

The distribution of Micro Vickers hardness in cross section and along center line are shown in Fig.2. The maximum hardness of the sharp edge is $720-730 \mathrm{HV}$. This hardness level almost corresponds to the hardness of martensite which contains 0.78 mass\% carbon. Several researchers $[14,18]$ had investigated hardness of Japanese swords on surface plane and cross section up to now. They had reported the maximum hardness level in sharp edge was about 700-820 HV. Japanese sword is very difficult to quench perfectly, because its composition is expressed in the modern type, "carbon tool steel" in which rarely contains effective alloying elements progressing hardenability.

It is found the hardend area was limited to sharp edge and a few distance from the sharp edge decreases hardness drastically. According to inside, slow quench associates to grow soft pearlite. Our observed hardness is typical one and we understand that the Japanese sword is a functionally graded materials produced in old Japan without knowing details of recently technique. 


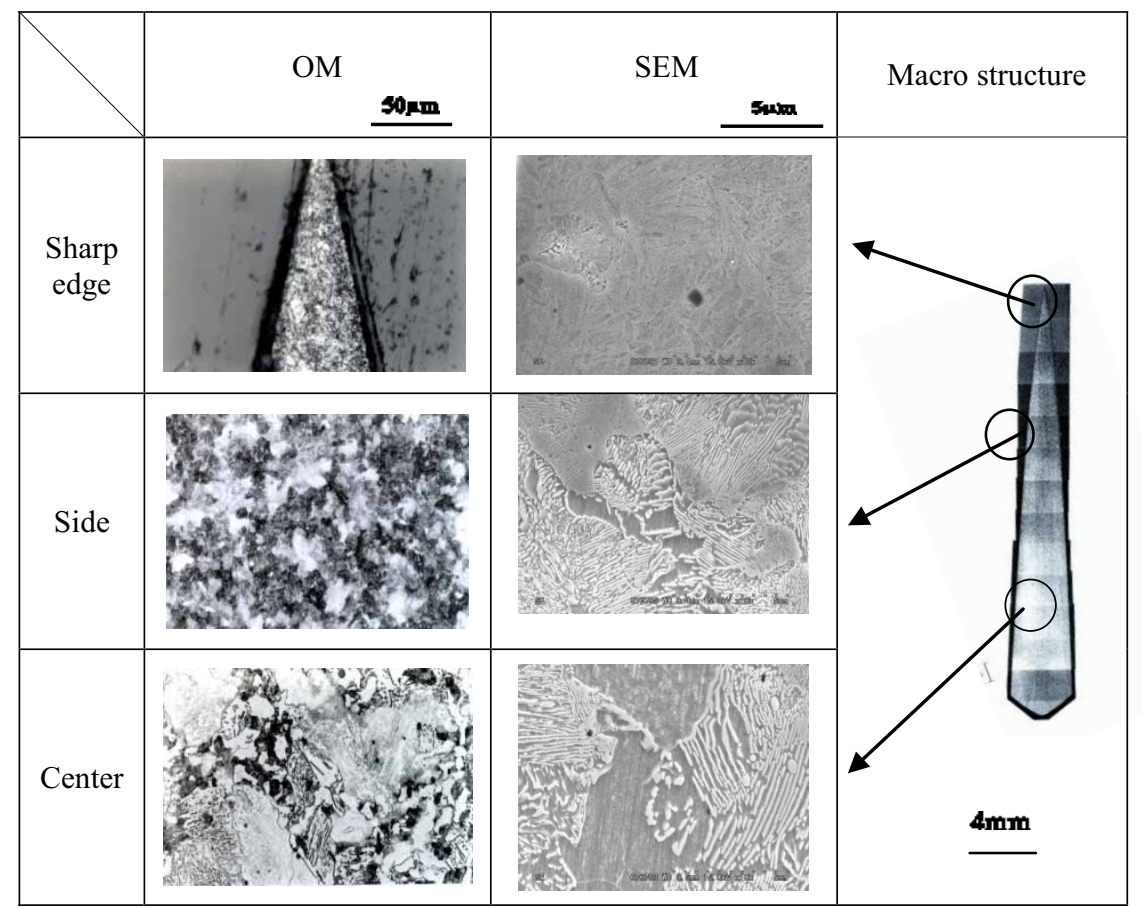

Fig. 1. Micro structure of cross section in Muramasa $2^{\text {nd }}$ by optical microscopy and scanning electron microscopy
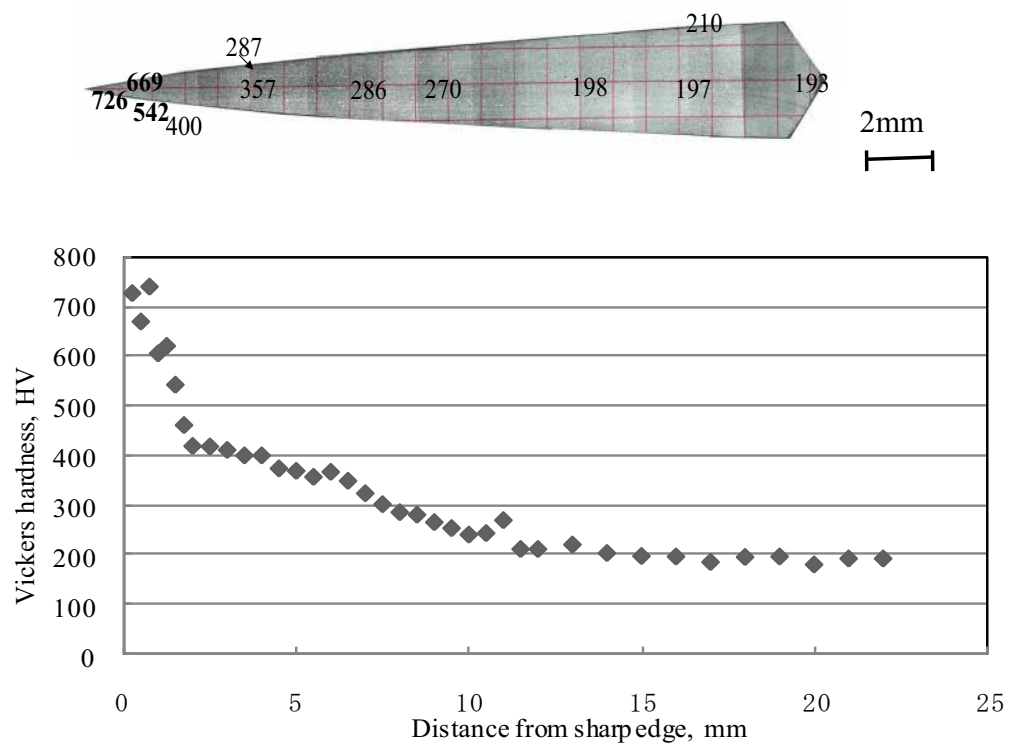

Fig. 2. The distribution of Micro Vickers hardness in cross section and along center line

\subsection{Non-metallic inclusion observation with OM and SEM-EDX}

Fig.3 shows the amount of non-metallic inclusions at three specific zones in Muramasa 2nd compared with ordinary steel contained 0.70 mass \% carbon. The amount of non-metallic inclusion in the sword is 50-100 times as much as ordinary steel. None of deoxidizer had been used in Tatara iron making process which is different from modern iron process. Lots of oxides and many inclusions originated from the slags remained in Tamahagane through the smelting reaction. In Fig. 4, the amount of inclusions is fewer and the sizes of those are 
finer in the sharp edge in comparison with the side and centeral part of the sword because of repeated forging effect in making sword.

Table 2 shows the composition of non-metallic inclusions in Muramasa 2nd. In this sword there are several kinds of inclusions such as $\mathrm{SiO}_{2}, \mathrm{FeO}, \mathrm{TiO}_{2}$ and $\mathrm{Al}_{2} \mathrm{O}_{3}$. On the contrary, ordinary steel has very low contents of inclusions and no $\mathrm{FeO}$ and $\mathrm{TiO}_{2}$. The detection of a lot of $\mathrm{Ti}$ oxides in non-metallic inclusion indicated that inclusion came from iron sand.

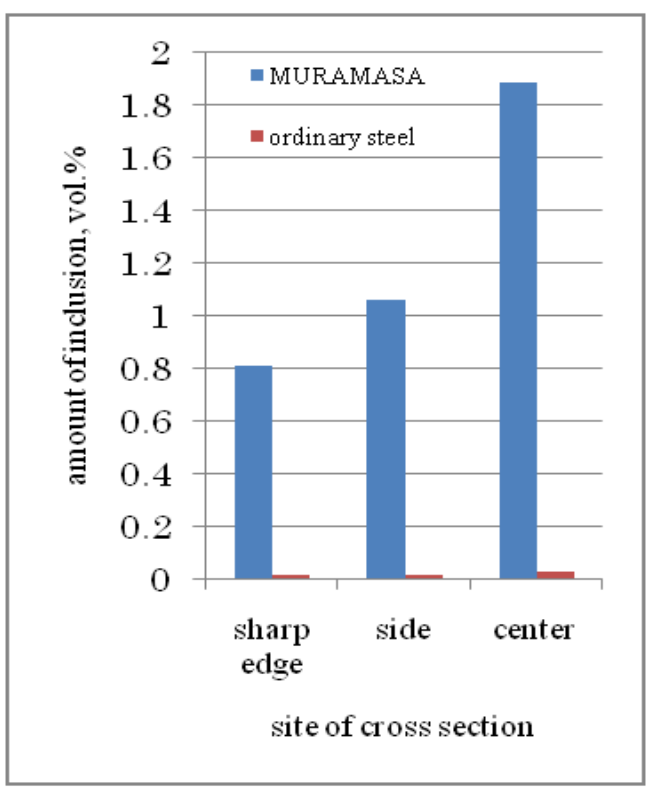

Fig.3. Amount of non-metallic inclusions at three specific zones in Muramasa 2nd comparing with ordinry steel

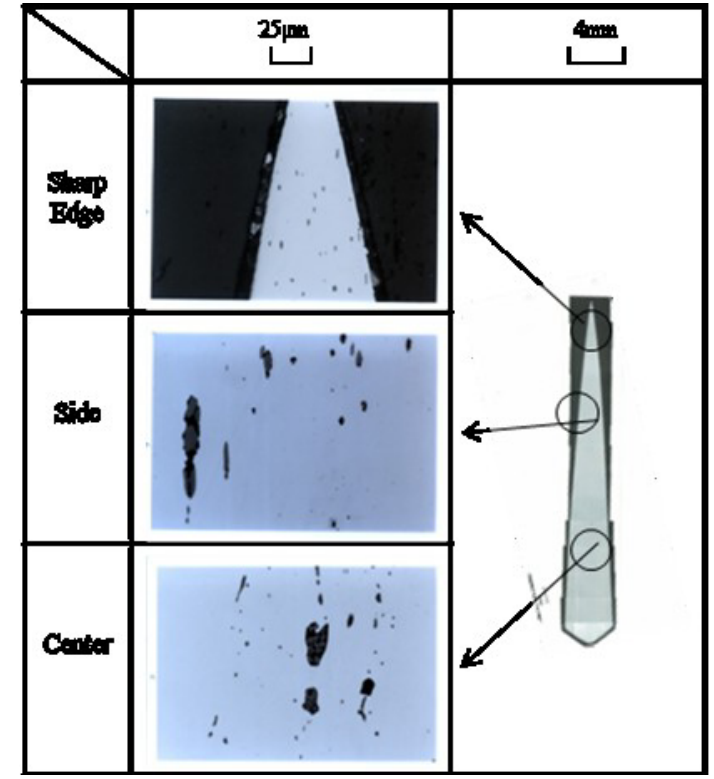

Fig.4. Distribution of non-metallic inclusions in three specific parts of cross section

Table 2. Chemical composition of inclusions analyzed

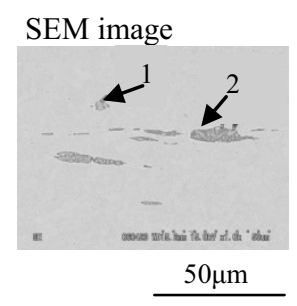

\begin{tabular}{|c|c|c|c|c|c|c|c|c|}
\hline \multicolumn{2}{|c|}{} & \multicolumn{7}{|c|}{ Quantitative analysis mass\% } \\
\cline { 2 - 10 } & & $\mathrm{FeO}$ & $\mathrm{SiO}_{2}$ & $\mathrm{Al}_{2} \mathrm{O}_{3}$ & $\mathrm{TiO}_{2}$ & $\mathrm{CaO}$ & $\mathrm{K}_{2} \mathrm{O}$ & $\mathrm{MnS}$ \\
\hline \multirow{2}{*}{$\begin{array}{c}\text { sharp edge of } \\
\text { Muramasa }\end{array}$} & 1 & 63.7 & 4.5 & 4.8 & 26.0 & & 0.4 & \\
\cline { 2 - 10 } & 2 & 19.7 & 50.3 & 13.2 & 2.2 & 7.2 & 6.2 & \\
\hline ordinary steel & - & & 26.3 & 17.0 & & & & 56.7 \\
\hline
\end{tabular}

\section{Conclusions}

A traditional Japanese sword produced by the 2nd generation of Muramasa has been characterized metallurgically. The features found are as follows :

(1) The micro structure of the sharp edge is lath martensite whereas that of the side and central parts is the fine or coarse pearlite structure.

(2) The micro hardness was found maximum in the sharp edge, which is consistent with the structure and carbon content of that zone.

(3) The non-metallic inclusions in the sword are more than those in the ordinary steel. The inclusions in the sharp edge are finer and the amout of inclusions is fewer than those in the side and central part.

(4) The dominant inclusions are $\mathrm{SiO}_{2}, \mathrm{TiO}_{2}, \mathrm{FeO}$ and $\mathrm{Al}_{2} \mathrm{O}_{3}$. The presence of these oxides justifies that the sword studied has been made by smelting the iron sand using 'Tatara' process. 


\section{Acknowledgment}

The authors are grateful to a leading polisher of Japanese sword, Mr. Setsuo Takaiwa and a first class registered architect, Hironari Katoh for useful suggestions. The authors also wish to acknowledge Mr. Tsuyoshi Kanaizumi for proper experimental support in Hitachi Metals, Ltd., Metallurgical Research laboratory. The authors also thank Hitachi Metals, Ltd., and the Board of Education in Yasugi City for financial support.

\section{References}

[1] O. D. Sherby, A. Suzuki, Tetsu-to-Hagane 66 (1980) 114-124 (in Japanese)

[2] H. Koizumi, "Nihontoh no kindaiteki kenkyu" Marzen (1933) pp.11-24 (in Japanese)

[3] S. Takaiwa, Y. Yoshihara, Leon and Hiroko Kapp, "The Art of Japanese Sword Polishing" Koudansha International (2006) pp.11-37

[4] N. Sasaki, T. Momono, Tetsu-to-Hagane 93 (2007) 792-798 (in Japanese)

[5] T. Suzuki, "Sakutoh no Dentoh gihoh" Rikougakusha (1994) pp.1-15 (in Japanese)

[6] M. Suenaga, "Nihon Kotoh kenkyu 5busho" Yoshikawa Koubunkan (1969) pp.1-9 (in Japanese)

[7] T. Suzuki, "Tataraseitetsu to Nihontoh no Kagaku" Yuzankaku (1990) pp.68-72 (in Japanese)

[8] T. Okuno, "Wakou Museum Zuroku” Wakou Museum (2001) pp.50-57 (in Japanese)

[9] S.Yamamoto, Tetsu-to-Hagane Overseas 1 (1961) 49-54

[10] K. Kiyonaga, Materia Japan 33(1994) 1453-1458 (in Japanese)

[11] J. Kozuka, Tetsu to Hagane 52 (1956) 1763-1778 (in Japanese)

[12] T. Kitamura, H. Katayama, Y. Murakawa, T. Okuno and T. Kishida, Ironmaking and Steelmaking 29 (2002) 276-280

[13] K. Tawara, "Nihontoh no kagakuteki kenkyu" Hitachi Hyouronsha (1953) pp.6-77 (in Japanese)

[14] T. Takahashi, T. Murakami, S. Okada and N.Fujii, Testu-to-Hagane 71(1985) 108-114 (in Japanese)

[15] M. Kitada, Collected Abstracts of 2008 Spring Meeting of The Japan Institute of Metals 142 (2008) 273 (in Japanese)

[16] T. Suzuki, “Tataraseitetsu to Nihontoh no Kagaku” Yuzankaku (1990) pp.165-167 (in Japanese)

[17] T. Maki, K. Tsuzaki and I. Tamura, Transactions ISIJ, 20 (1980) 207-214

[18] T. Suzuki, “Tataraseitetsu to Nihontoh no Kagaku” Yuzankaku (1990) pp.148-155 (in Japanese) 